\title{
The implementation of the occupational health and safety management system according to OHSAS 18001/2007 in a Moroccan telecommunication company
}

\author{
Latifa Benakka ${ }^{1, *}$, Loubna Zogaam Gharbi $^{2}$, Said Bacroume $^{3}$, Zohra Bejjaji $^{1}$, and Mahjoub Aouane ${ }^{2}$ \\ ${ }^{1}$ Laboratory Geosciences of Natural Resources, Faculty of Sciences IbnTofail University Kenitra Morocco. \\ ${ }^{2}$ Laboratory Agroresource Biotechnology Environment and Quality, Faculty of Sciences, IbnTofail University, Kenitra, Morocco. \\ ${ }^{3}$ Rabat Scientific Institute / Department of Chemie, Faculty of Science Mohammed V Rabat, Morocco..
}

\begin{abstract}
Integrated environmental, health and safety management systems are a new management paradigm in modern organizations. These systems are built on the ISO 14001 and OHSAS 18001 standards, based on risk prevention and the precautionary principle. The study is carried out in a telecommunications company in Morocco. The objective is the definition of an approach that will promote the protection of its employees against the risks they face and not only prepare them for obtaining safety certification. It has become necessary to have a new approach to occupational safety, which is part of the overall management of the company, and this project has touched him. In fact, this study has tried to guarantee the best working conditions and the presentation of the employees' rights, as well as to reduce the indirect costs resulting from occupational diseases and accidents at work. In other words, the internal audit carried out demonstrated compliance with the main requirements of OHSAS 18001 regarding environmental, health and occupational safety management.
\end{abstract}

\section{Introduction}

An Environmental Management System is a tool, an organizational mode that should enable a company to structure its environmental management and improve its environmental performance.

The subject of integrated management systems in terms of quality, environmental and occupational health and safety management is increasingly considered part of the management portfolio of the organization [1 - 5]. Integrated management systems have been discussed and written by both quality professionals and academic researchers for several years [6,7].

This article focuses on the implementation analysis of an integrated management system for environmental, health and safety at work according to the OHSAS 18001 standard (IMS). It will attempt to contribute to the understanding of the issues posed and the expected effects following the implementation of an IMS in a company.

Environmental management has a close relationship with health and quality of life and also represents a means to achieve certain material and energy savings, to improve the company's image or to develop a competitive advantage over the competition [8]. This is why, since the late 1980 s, several national environmental standards have appeared in several countries before the publication of the ISO 14001 standard.

Safety at work is becoming a new issue of competitiveness and an instrument for steering and control. It is now an integral part of any risk management policy for companies [9]. In this sense, the increase in industrial accidents at work requires companies to implement a set of measures and means to guarantee the safety of personnel and the protection of property $[10,11]$. To ensure the safety of personnel, the company must adopt effective methods and means. Among the actions to be taken to improve health and safety at work are:

- Analyze the sources of risk with the usual methods of risk analysis (FMEA, ...),

- Eliminate sources of stress and mental fatigue,

- Smooth the workload and the work rhythm: too heavy a workload or too fast a work rhythm creates pressure and tension on the staff, which may affect their safety,

- Improve workstation ergonomics,

- Equip workstations with pictograms to better indicate health and safety requirements.

\section{Materials and methods}

Health is the prerequisite for the well-being of the individual and is a major determinant of quality of life. It is therefore important to pay particular attention to maintaining healthy living conditions. In this respect, the world of work is of considerable importance. "Healthy workstations" promote a positive work climate and make a significant contribution to maintaining motivation,

\footnotetext{
*Corresponding author: latifa.benakka@uit.ac.ma
} 
productivity and creativity, which among other things increases employee loyalty.

The Moroccan Labor Code Bulletin published in Official No. 5210 of Thursday, May 6, 2004 requires the employer to take all measures to prevent occupational accidents and diseases and to protect the health of workers, all measures that experience has shown to be necessary, that the state of the art allows to apply and that are adapted to the conditions of the administration.

The implementation of a quality approach according to the OHSAS $18001 \mathrm{~V} 2007$ standard must be structured and planned in order to guarantee its success. Indeed, everything starts with a precise diagnosis evaluating the company in action in relation to the requirements of the standard. On the basis of this evaluation an action plan will be deduced and will then represent the different actions for its implementation.
Various missing procedures have been established and written in accordance with practices to be adopted considering all the risks and establishing the various commitments necessary to achieve the objectives.

\section{Diagnostic}

The diagnostic stage allows data collection and processing. Indeed, data collection is generally done through a questionnaire (see table 1) that is structured around different stages of progress:

- Stage 1: Security management.

- Stage 2: Environmental management.

- Stage 3: Quality management.

- $\quad$ Stage 4: Personnel management.

Table 1. Diagnostic representation of the company

\begin{tabular}{|c|c|c|c|}
\hline \multirow{2}{*}{ Requirement } & \multicolumn{2}{|c|}{ Report } & \multirow{2}{*}{ Recommandation } \\
\hline & Yes & No & \\
\hline $\begin{array}{l}\text { Is it communicated to all staff with the intention of } \\
\text { making employees aware of their individual } \\
\text { obligations regarding health and safety at work? }\end{array}$ & & $\checkmark$ & $\begin{array}{l}\text { Define and take into account the principles of risk } \\
\text { prevention in the OHS policy (remove hazards, if not } \\
\text { reduce risks by collective prevention measures, if not } \\
\text { reduce risks by individual prevention measures). }\end{array}$ \\
\hline $\begin{array}{l}\text { Have all hazards and hazardous situations associated } \\
\text { with each workstation (or work department) within the } \\
\text { company been identified? }\end{array}$ & & $\checkmark$ & Identify all hazards in each work department \\
\hline $\begin{array}{l}\text { Are the means implemented to control risks at each } \\
\text { workstation properly identified and evaluated? }\end{array}$ & & $\checkmark$ & $\begin{array}{l}\text { Identify the preventive actions relevant to the control } \\
\text { of the most critical risks.. }\end{array}$ \\
\hline $\begin{array}{l}\text { Have all applicable regulatory requirements (beyond } \\
\text { text references) been identified by the company? }\end{array}$ & & $\checkmark$ & Identify applicable regulatory requirements. \\
\hline $\begin{array}{l}\text { Is there a procedure for identifying and assessing } \\
\text { regulatory and other requirements? }\end{array}$ & & $\checkmark$ & Establish a regulatory monitoring procedure \\
\hline $\begin{array}{l}\text { Is the achievement of OHS objectives planned (OHS } \\
\text { program)? }\end{array}$ & & $\checkmark$ & $\begin{array}{l}\text { Plan the achievement of SMART OHS improvement } \\
\text { objectives. }\end{array}$ \\
\hline $\begin{array}{l}\text { Are positions requiring specific OHS skills, training } \\
\text { and/or experience identified and recorded? }\end{array}$ & & $\checkmark$ & Establish a continuing education procedure \\
\hline $\begin{array}{l}\text { Is there an OHS awareness procedure for all company } \\
\text { personnel? }\end{array}$ & & $\checkmark$ & Establish an awareness procedure \\
\hline $\begin{array}{l}\text { Are employees consulted when implementing any } \\
\text { changes affecting health and safety in the workplace? }\end{array}$ & & $\checkmark$ & $\begin{array}{l}\text { Predicting staff involvement in the changes } \\
\text { affecting OHS. }\end{array}$ \\
\hline $\begin{array}{l}\text { Does the OHS management system documentation } \\
\text { include a description of the scope of the OHS } \\
\text { management system? }\end{array}$ & & $\checkmark$ & Define the scope of the documented OHS system \\
\hline $\begin{array}{l}\text { Are the documents required by the OHS management } \\
\text { system and by this OHSAS standard controlled? }\end{array}$ & & $\checkmark$ & $\begin{array}{l}\text { Establish the procedure for the control of external } \\
\text { documents. }\end{array}$ \\
\hline $\begin{array}{l}\text { Are OHS-risk workstations deemed important } \\
\text { identified? }\end{array}$ & & $\checkmark$ & $\begin{array}{llllll}\begin{array}{l}\text { Identify all } \\
\text { assessment. }\end{array} & \text { risk positions during risk } \\
\end{array}$ \\
\hline $\begin{array}{l}\text { Does every accident result in a recording and analysis } \\
\text { of the causes? }\end{array}$ & & $\checkmark$ & Establish the incident management procedure. \\
\hline $\begin{array}{l}\text { Is the analysis of OHS risks at the workstation } \\
\text { eventually updated following corrective or preventive } \\
\text { action? }\end{array}$ & & $\checkmark$ & $\begin{array}{l}\text { Provide for the updating of the OHS risk analysis } \\
\text { following corrective and preventive actions }\end{array}$ \\
\hline $\begin{array}{l}\text { Must the records be and remain legible, identifiable } \\
\text { and traceable to the activities concerned? }\end{array}$ & & $\checkmark$ & $\begin{array}{l}\text { Establish a procedure for managing the records must } \\
\text { be legible, identifiable and allow the activities } \\
\text { concerned to be found. }\end{array}$ \\
\hline $\begin{array}{l}\text { Is each deviation noted during the audits processed } \\
\text { (non-conformity sheet)? }\end{array}$ & & $\checkmark$ & Establish an internal audit procedure. \\
\hline Are there periodic OHS management reviews? & & $\checkmark$ & Implement the OHS management review procedure. \\
\hline $\begin{array}{l}\text { Does management provide feedback on the } \\
\text { effectiveness of the safety system? }\end{array}$ & & $\checkmark$ & $\begin{array}{l}\text { To provide management input on the effectiveness of } \\
\text { OHS during the management reviews. }\end{array}$ \\
\hline
\end{tabular}




\section{Result}

The results of this research will help to better understand the new paradigm of integrated environmental and occupational health and safety management in order to improve occupational and environmental health and safety practices and policies $[12,13]$.

The risk assessment using the FMEA method has identified the existence of the following risks: the risk of road accidents, the risk of falls due to working at height on ladders, scaffolding and towers, and the risk of electrocution. The results of this assessment carried out at the company, prove the need for operational and organizational control, and mainly concerning manual operations, operators and technicians, Within this framework, commitments, procedures, forms and technical data sheets have been developed to improve employee safety of employees, take stock of the progress of action plans (corrective actions, safety studies, administrative requests ...). Among the institutions that are established:

* Establishment of a Commitment to respect good driving practices.

* Establishment of a Commitment to hand over personal protective equipment (PPE).

* Establishment of a Checklist for the maintenance of your car.

* Drawing up of a PPE Checklist. (See figure 1).

* Establishment of the following procedures:

- Procedure for managing the driving of vehicles: aims to clarify the provisions put in place by the company for the management of the driving of vehicles. Its objective is to control the measures necessary to ensure safe travel.

- PPE management procedure: the purpose of this procedure is to describe the management of the protective equipment made available to operators in order to guarantee their safety.

- Incident management procedure: aims to explain the provisions put in place by the company for the management of incidents and risks on site. Its objective is to restore normal service operations as quickly as possible and minimize the negative impact on the service provided to the customer and on employees.

- Complaints handling procedure: aims to explain the provisions put in place by the company to ensure the handling of customer complaints. Its objective is to ensure that the company listens to customers in order to improve the services offered by the company.

\subsection{Action plan}

After the initial diagnosis, it is necessary to make a risk identification to measure and control the risks. Table 2 summarizes this identification. The analysis of this step allows to determine and identify the transformation processes and the individual and collective protective equipment that have a direct impact on the QSE aspects and that require special attention. It is therefore a question of sorting and prioritizing the equipment according to their criticality in order to optimize resource management and to target the company's actions (recruitment, training, etc.) towards the main areas. Based on the FMEA method (Failure Mode Analysis of their effects and criticality), it is preferable to propose a criticality matrix using the Q, S, E criteria to prioritize the equipment and/or processes having an impact on this triptych: Quality effect (Q): reflects the impact of an equipment or process on the quality of products and/or services;

* Safety effect (S): reflects the impact of an equipment or process on the safety of goods and/or people;

* Environmental Effect (E): reflects the impact of an equipment or process on the environment;

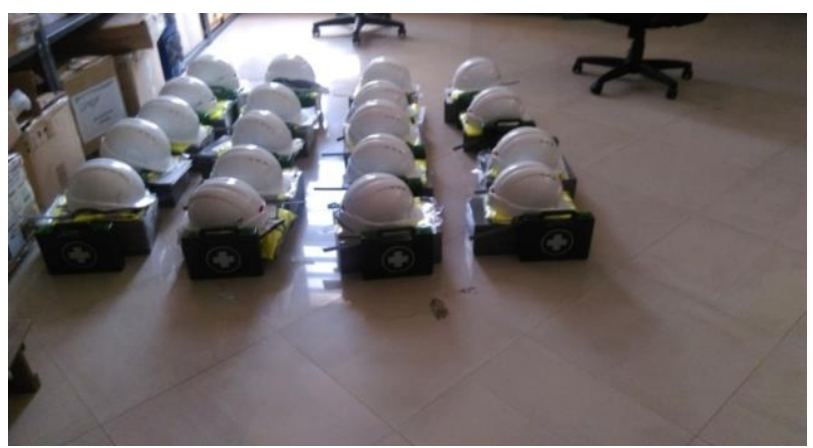

Fig.1. Personal Protective Equipment (PPE)

\subsection{Internal audit:}

This audit enabled to identify the following discrepancies shown in Figure 2:

- $19 \mathrm{NC}: 3$ related to documentation, 9 related to application and 7 related to documentation and application;

- 8 R: 4 related to the application, 3 related to the documentation and one related to the documentation and application;

In order to ensure the implementation and follow-up of the Corrective Actions / Preventive Actions (CA/AP), the deviations identified during this audit, It is recommended to record them on the Continuous Progress Sheets (CPS) and when the corrective action is common for 2 or more deviations; Non-Compliance or Remarks (NC or R) they are grouped together in a single CPS.

This audit enabled to define the documents to be modified in order of priority; the priority is related to the number and seriousness of the discrepancies identified; therefore, it seemed judicious to group these discrepancies by chapter of the health and safety in the workplace manual in the form of the following summary table 3.

From Figure 3, it is clear that the large number of discrepancies is linked successively to Chapter VI of the Management Review, which shows that this tool requires a great deal of effort to master. The same is true for chapters IV and V of the verification, which is explained by the fact that the system is still young and that its maturity certainly improves this chapter. 
Table 2. Representation of an action plan

\begin{tabular}{|l|l|l|l|l|l|}
\hline \multicolumn{2}{|c|}{ Requirement } & \multicolumn{2}{|c|}{ Report } & \multicolumn{2}{l}{ Recommandation } \\
\cline { 3 - 5 } & Yes & No & \\
\hline \multicolumn{3}{|c|}{ Hazard identification, risk assessment and control measures } \\
\hline $\begin{array}{l}\text { Are the workstations (or work sections) subject to an } \\
\text { exhaustive inventory? }\end{array}$ & $\checkmark$ & Make an exhaustive inventory of each workstation \\
\hline $\begin{array}{l}\text { Are these workstations (or work departments) described } \\
\text { in terms of the tasks to be performed? }\end{array}$ & & $\checkmark$ & $\begin{array}{l}\text { Establish an organizational manual describing their } \\
\text { entities and their tasks. }\end{array}$ \\
\hline $\begin{array}{l}\text { Have all hazards and hazardous situations associated } \\
\text { with each workstation (or work department) within the } \\
\text { company been identified? }\end{array}$ & & $\checkmark$ & Identify all hazards in each work department \\
\hline $\begin{array}{l}\text { Has a risk assessment of these hazards and hazardous } \\
\text { situations been carried out for each workstation (or } \\
\text { work department)? }\end{array}$ & & $\checkmark$ & $\begin{array}{l}\text { Make a risk assessment for each hazard according to the } \\
\text { FMEA method. }\end{array}$ \\
\hline Have the results of this risk analysis been recorded? & & $\checkmark$ & Record the results of the risk analysis. \\
\hline $\begin{array}{l}\text { Is this risk analysis kept up to date (evolution of } \\
\text { activities, knowledge workstations)? }\end{array}$ & $\checkmark$ & Keep the risk assessment up to date. \\
\hline $\begin{array}{l}\text { Is there a risk analysis procedure for workstations? } \\
\text { (who does what, when and how) }\end{array}$ & & $\checkmark$ & Implement the risk analysis procedure. \\
\hline $\begin{array}{l}\text { Does this procedure describe the method used to assess } \\
\text { risk significance and acceptability? }\end{array}$ & & $\checkmark$ & $\begin{array}{l}\text { Specify the FMECA method on the risk analysis } \\
\text { procedure. }\end{array}$ \\
\hline $\begin{array}{l}\text { Are the means implemented to control risks at each } \\
\text { workstation properly identified and evaluated? }\end{array}$ & & $\checkmark$ & $\begin{array}{l}\text { Identify preventive actions relevant to control } \\
\text { of the most critical risks }\end{array}$ \\
\hline $\begin{array}{l}\text { Are work situations associated with residual risks } \\
\text { deemed significant identified? }\end{array}$ & & $\checkmark$ & $\begin{array}{l}\text { Identify work situations associated with residual risks } \\
\text { deemed important. }\end{array}$ \\
\hline
\end{tabular}

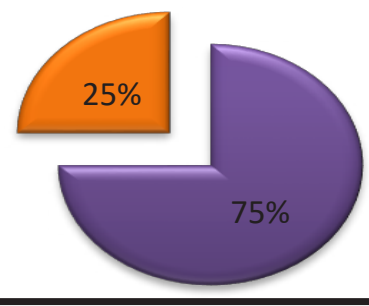

Application deviations

$\square$ Documentation deviationdeviation

Fig.2. Representation of application and documentation deviation in terms of $\%$.

Table 3. Summary table of deviations by chapter

\begin{tabular}{|c|c|}
\hline The Chapter & The Deviations \\
\hline Chapter 4.1: General Requirements & 1 \\
\hline Chapter 4.2: Health and Safety Policy & 1 \\
\hline Chapter 4.3 : Planning & 1 \\
\hline Chapter 4.4: Implementation and operation & 14 \\
\hline Chapter 4.5: Audit & 10 \\
\hline Chapter 4.6: Management Review & 19 \\
\hline
\end{tabular}

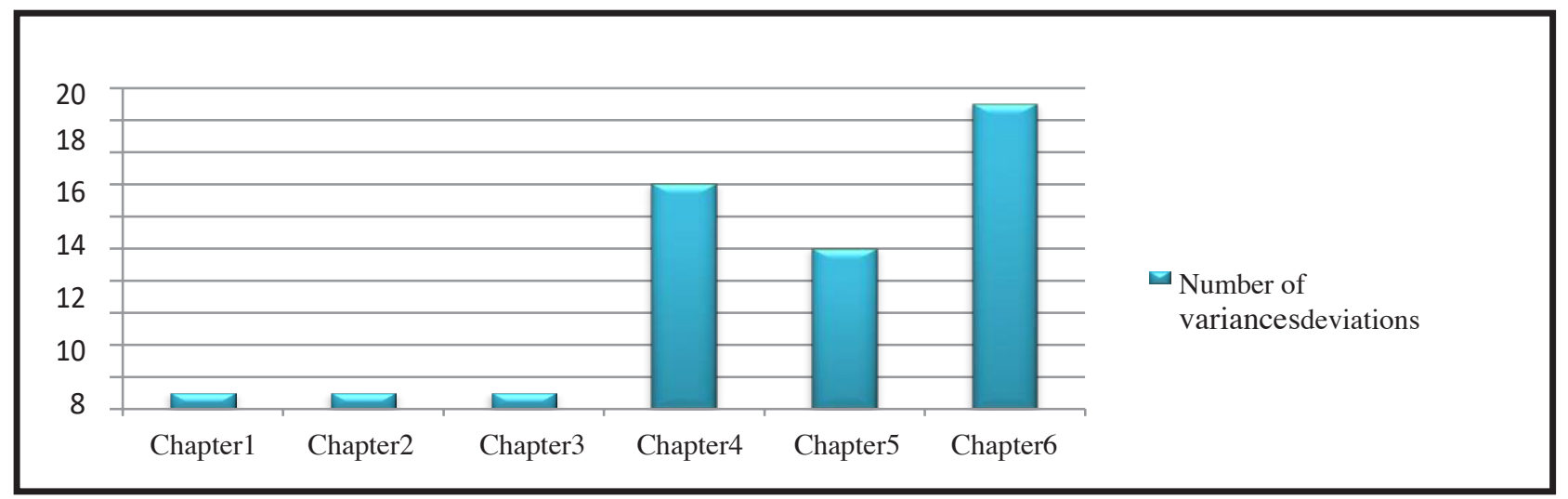

Fig. 3. Graphic representation of variances by chapter 


\section{Discussion}

Based on the risk identification, it can be seen that the average risks recorded at the company are the most dominant followed by low risks and critical risks are the most dominant. Therefore, it is necessary to analyze them in order to eliminate them or at least reduce them. This makes it possible to notice that the most critical risks are related to traffic accident hazards due to: speeding, reverse, false passing, fatigue.....And to note that a large part of the risks of average criticality are linked to machine and equipment hazards, through the establishment of networks (anti-error systems, ...) and site supervision.

OHSAS leads to a certificate of approval and can be implemented in any type of organization, regardless of size. It is structured in a management mechanism spelled out in five steps: commitment, planning, implementation, control and management review. It contains 18 requirements that focus on continuous performance improvement in the control of occupational health and safety risks [13]. Like the ISO 9000 and ISO 14001 standards with which it is compatible, OHSAS 18001:2007 does not set requirements in terms of the level of performance to be achieved. What differentiates it from other occupational health and safety management systems is the importance given to risk management and, more recently, to occupational health. OHSAS18001:2007 requires the systematic and detailed identification of hazards in the workplace, and risk analysis covering all operational conditions.

\section{Conclusion and Recommendations}

The study carried out made it possible, on the one hand, to set up an OHS system in accordance with OHSAS $18001 \mathrm{v} 2007$ and, on the other hand, the implementation of the participatory approach which is the keystone for staff motivation.

As well as being closely related to the health and safety of personnel, environmental management also represents a means of achieving certain material and energy savings, improving the company's image and developing a competitive advantage over the competition.

The completion of this study required the implementation of evolution and evaluation tools that enabled to successfully implement the OHS approach within the company.

The results obtained do not mean that the system is closed but mean that the OHS system is evolving, because the OHS system should not be fixed but on the contrary it should always be readapted to the environment: edition of new standards, appearance of new risk analysis methods, changes in responsibilities and internal organization, etc. assurance of the continuous improvement of the OHS system requires important changes such as:

- Maintenance of the monitoring system through weekly Continuous Progress Scorecard (CPS) meetings;
- Facilitation of OHS training sessions for all staff as part of the continuing education project;

- Completion of the OHS system implementation process;

- The evolution of customer relations ;

- Deployment of general high-level objectives into specific low-level objectives;

- Implement the approach introduced by the company's certification at the end of 2018

- Raising staff awareness of the importance of their performance, evaluating and discussing it in order to refocus their future actions in relation to the company's expectations and directing them towards better customer satisfaction.

\section{References}

1. Stamou, T. (2003), integrated Management Systems in Small Medium-Sized Enterprises: Theory and Practice.

2. Patience, A. (2008), Integrated Management Systems - A qualitative study of the levels of integration of three Danish Companies, Thesis submitted for the degree of Master of Science in Engineering in Environmental management.

3. Poulida, O., Constantinou, L. (2010), Development of an Integrated Management System in a Small and Medium-size oil Industry: Safety, Energy and Environment

4. Matias, J.C.D.O., Coelho, D.A. (2002), The integration of the standards systems of quality management, environmental management and occupational health and safety management, International Journal of Production Research, Vol. 40, part 15, pp.3857-3866.

5. Asif, M. (2008), Corporate Motivation for Integrated Management System Implementation, Why do Firms Engage in Integration of Management Systems: A Literature Review \& Research Agenda, pp.2-21.

6. Tang, J. (2003). Corporate Culture and Integrated Management Systems: A case study of the UK Construction Industry, University of East Anglia, 2003.

7. McDonald, M., Mors, T., Phillips, A. (2003), Management System; Integration: Can It Be Done? QUALITY PROGRESS, 67-73 Militaru, R.

8. Jacqueson L., Intégration de l'environnement dans l'entreprise : proposition d'un outil de pilotage du processus de création de connaissances environnementales. Thèse de doctorat de l'école nationale supérieure d'arts et métiers.19 avril 2002.

9. Stimec A., Bertrand T., Michel X., Contribution à la compréhension des facteurs organisationnels et managériaux de la santé au travail : le cas d'une usine d'un équipementier automobile. Congrès international «outils, modes et modèles» Fribourg Suisse 2007.

10. Gaultier-Gaillard S., Pech P., Galea P., Gestion des risques et culture de sûreté : le cas du vecteur badge, véritable « passeport pour l'entreprise de demain » 
Revue française de gestion industrielle, Vol. 28, $\mathrm{N}^{\circ}$ 1 - 2009;

11. Bahri S., Mabrouk H., L'Intégration de la Sécurité dans les Systèmes Technologiques de l'Information etde la Communication. 5 th International Conference: Sciences of Electronic, Technologies of Information and Telecommunications, March 22-26, 2009 - TUNISIA.

12. ISO 14001, Système de management environnemental - exigences et lignes directrices pour son utilisation. 2ème édition Paris. Novembre2004.

13. OHSAS 18001, Occupational Health and Safety Management Systems - Requirements OHSAS2007 